\title{
A Novel Approach to Numerical Modeling of Metabolic System: Investigation of Chaotic Behavior in Diabetes Mellitus
}

\author{
Payam Sadeghi Shabestari, ${ }^{1}$ Karthikeyan Rajagopal $\left(\mathbb{D},{ }^{2,3}\right.$ Bahareh Safarbali, ${ }^{1}$ Sajad Jafari ${ }^{1},{ }^{1}$ \\ and Prakash Duraisamy ${ }^{3}$ \\ ${ }^{1}$ Biomedical Engineering Department, Amirkabir University of Technology, Tehran 15875-4413, Iran \\ ${ }^{2}$ Department of Electrical and Communication Engineering, The PNG University of Technology, Lae, Papua New Guinea \\ ${ }^{3}$ Centre for Non-Linear Dynamics, Defense University, Bishoftu, Ethiopia
}

Correspondence should be addressed to Karthikeyan Rajagopal; rkarthiekeyan@gmail.com

Received 3 March 2017; Accepted 6 June 2017; Published 30 September 2018

Academic Editor: Dan Selișteanu

Copyright (c) 2018 Payam Sadeghi Shabestari et al. This is an open access article distributed under the Creative Commons Attribution License, which permits unrestricted use, distribution, and reproduction in any medium, provided the original work is properly cited.

\begin{abstract}
Although many mathematical models have been presented for glucose and insulin interaction, none of these models can describe diabetes disease completely. In this work, the dynamical behavior of a regulatory system of glucose-insulin incorporating time delay is studied and a new property of the presented model is revealed. This property can describe the diabetes disease better and therefore may help us in deeper understanding of diabetes, interactions between glucose and insulin, and possible cures for this widespread disease.
\end{abstract}

\section{Introduction}

Diabetes, technically called diabetes mellitus, is referred to types of disorders in the metabolic processes of the human body in which the controlling mechanism of sugar level in blood is disrupted. In these cases, insulin, the mainstay controlling element, is either not secreted or its presence is ignored by body cells [1]. There are three types of diabetes: type 1 , type 2 , and gestational diabetes. Type 1 diabetes is all about insulin. In this type of diabetes, the body's immune system intercepts insulin-releasing cells and destroys them. This type of diabetes accounts for 5 to 10 out of 100 diabetic people. In type 2 diabetes, the body is not able to use insulin in the right way. This type of diabetes is the most common in the world, and around 90 to 95 percent of diabetics have type 2. A third type of diabetes, gestational diabetes, is a temporary condition that occurs during pregnancy. It affects approximately two to four percent of all pregnancies [2-5].
The function of insulin alters for each organ in the human body, so the effects of environmental factors like stress and nourishing habits may cause blood glucose shift. As observed in various countries, diabetes is discernibly widespread and there is an increasing number of people suffering from this. Hence, the potentially lethal symptoms of the illness necessitate more meticulous treatments and precautionary activities. The essence for such cure procedures is even more accentuated in contemporary hectic life in which people have an increasing penchant to be nourished by artificially cultivated foods and do less exercise. The number of people suffering from this disease was approximately 415 million in 2015 with equal shares of both genders, which accounted for $8.3 \%$ of the overall adult population of the world. And nearly 1.5 to 5 million people have died because of diabetes every year between years 2012 and 2015 worldwide [1].

Speaking of the reasons triggering this illness, many elements can cause this irregularity behavior in the body, such 
as genetic factors inherited through generations that fertilize the body for other factors of the disease to easily disrupt the metabolic system, obesity due to malnutrition and urbanization as consequent of modern lifestyle, side effects of taking specific drugs like glucocorticoids and thyroid hormone, progression of other illnesses, and many other factors which cannot be wholly included [1]. Knowing about the causes of disease enables scientists to develop meditative procedures.

Besides the paramount and distinctive importance of experimental researches for developing effective treatment protocols, studying and developing mathematical models of glucose-insulin bilateral interplay have had an essential role in accelerating the research processes and making breakthroughs in this field by saving both money and time. Conventionally, it was believed that a linear relationship defines the mechanism of glucose-insulin negative feedback system. A linear model for diabetes assumes that the relationship between glucose and insulin concentration could be studied in isolation from other components [6]. In contrast, nonlinear models proposed in previous studies assume that the relationship between components is not always linear [7] and it could depend on initial blood glucose level [8]; moreover, they revealed the fact that statistical properties of the profile in some patients could alter substantially $[6,9,10]$. In glucose-insulin system, interactions between components are responsible for the overall behavior of the system, which makes this system a complex one. The basic structure of insulin secretion system is a negative feedback controller operating between two elements, namely, the pancreatic $\beta$-cells and plasma glucose concentration of the blood contacting these cells. A high level of glucose concentration is acquired, for example, when having a snack which provokes the production and release of insulin leading to a decrease in glucose levels by increasing the consumption rate of the extra sugar or initiation of storage process. On the contrary, if plasma blood is experiencing low levels of glucose concentration, insulin secretion is halted, preventing further declination of blood sugar. In this case, the metabolic system shifts condition from absorptive to postabsorptive [11, 12].

As delineated in the preceding paragraph, various mathematical models have been proposed in attempts to simulate the relation between plasma glucose concentration and plasma insulin concentration more accurately, so that scientists will be able to have an elaborate perspective of this metabolic interaction [13-17]. It is wondering that the recently submitted models show some kind of chaotic behavior in the mechanism of malfunctioning metabolic system which is revealed in the current study.

The investigation of chaotic dynamics has attracted the foci of many scientists, and a great deal of effort is put in this field as it has provided a successful method for studying biological systems [18-23]. Moreover, this novel vantage point of studying biological phenomena has made revolutionary effects on developing biological system models [24-27].

Because of the complexity of the system, the model that has been studied in this paper is a nonlinear model. The nonlinear model that we study reflects the relationship between injected insulin and blood glucose response. The studies about variation in the blood glucose indicate a chaotic component.

In the second section, the dynamical properties of the last presented model for glucose and insulin concentration are investigated. Eventually, conclusion remarks are given in Section 4 .

\section{Mathematical Model}

In 1964, Ackerman et al. [16] proposed a linear model for glucose tolerance test consisting of two ordinary differentials (1), as demonstrated below.

$$
\begin{aligned}
& \frac{d x}{d t}=a_{1} y(t)-a_{2} x(t)+C_{1}, \\
& \frac{d y}{d t}=-a_{3} y(t)-a_{4} x(t)+C_{2}+I(t),
\end{aligned}
$$

where $x(t)$ is the insulin concentration and $y(t)$ is the blood glucose concentration. $a_{1} y(t)$ is the rate of increase in insulin concentration due to increase in glucose concentration, $a_{2} x(t)$ represents the rate of insulin reduction, $a_{3} y(t)$ represents the rate of glucose reduction independent to insulin, and $a_{4} x(t)$ represents the rate of glucose removal due to insulin secretion. $C_{1}$ and $C_{2}$ are positive constants, and $I(t)$ is the rate of increase in blood glucose concentration due to absorption in the gastrointestinal system.

In 1987, Bajaj et al. [15] proposed a nonlinear mathematical model for glucose-insulin feedback system which incorporated $\beta$-cell kinetics. The mathematical relationships for the model are formulated as shown in

$$
\begin{aligned}
& \frac{d x}{d t}=R_{1} y-R_{2} x+C_{1}, \\
& \frac{d y}{d t}=\frac{R_{3} N}{z}-R_{4} x+C_{2}, \\
& \frac{d z}{d t}=R_{5} y(T-z)+R_{6} z(T-z)-R_{7} z,
\end{aligned}
$$

where $x(t)$ and $y(t)$ represent the insulin and glucose concentrations, respectively, and $z(t)$ represents the number of $\beta$-cells. It has been discovered that $\beta$-cells have an essential role in regulating glucose and insulin concentration. Recent studies indicate two delays in glucose-insulin feedback control system [28-32]. Two important time lags can be noticed in the system, the lag in insulin secretion in response to an increase in blood glucose concentration, $\tau_{g}$, and hepatic glucose response lag, $\tau_{i}$.

In the current research, we study a nonlinear mathematical model for glucose-insulin feedback control system by incorporating the enhanced delay differential equations embracing $\beta$-cells proposed by the model presented by Sarika et al. [28]. The modified model is the compound of the model proposed by Bajaj et al. [15] and the one suggested by Sarika et al. [28]. The resulted model is the one presented by 


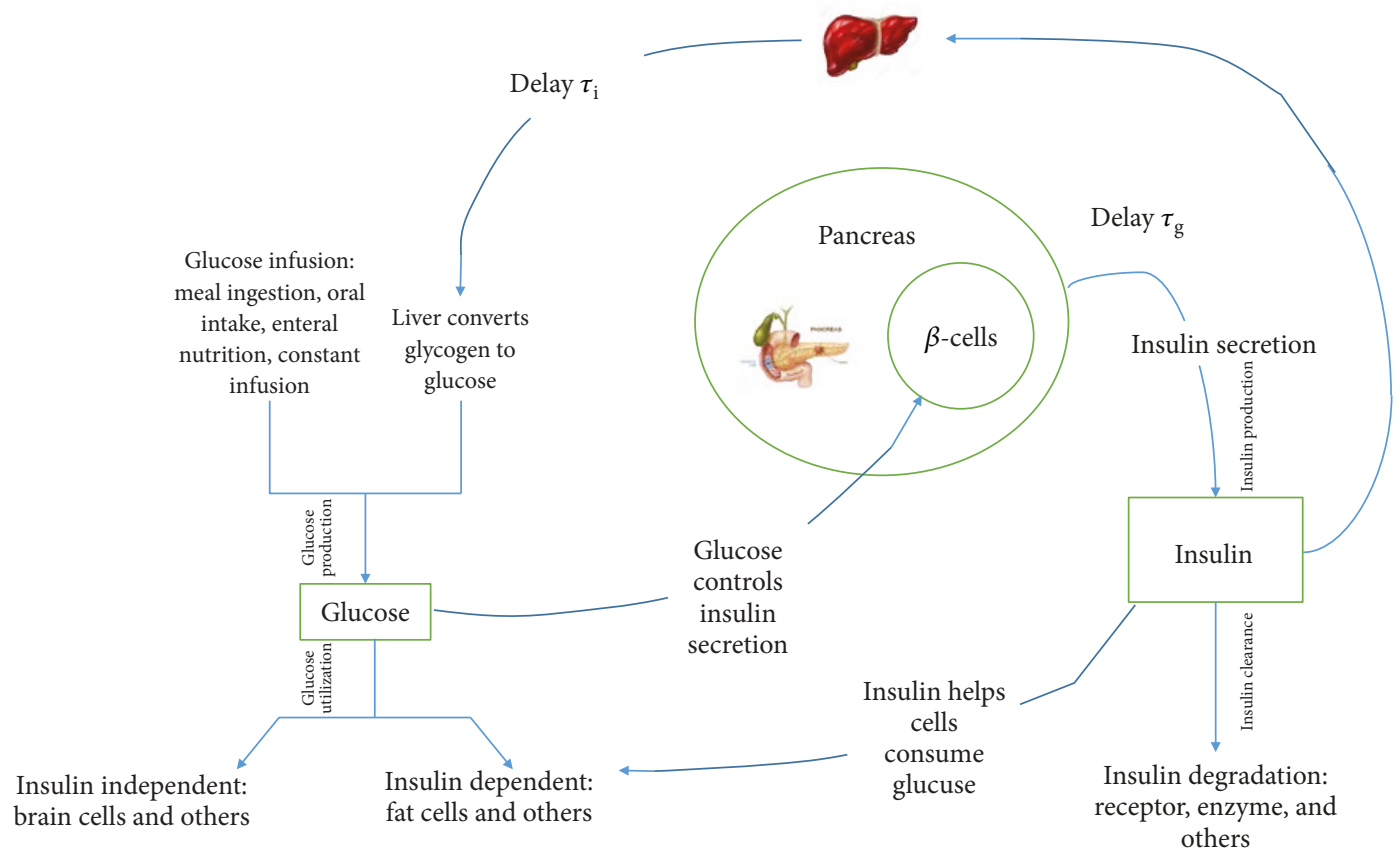

FIgUre 1: Two time delays in glucose-insulin system [11].

Chuedoung et al. [11] (Figure 1), which can be presented in delay differential equations as follows:

$$
\begin{aligned}
& \frac{d x}{d t}=r_{1} y\left(t-\tau_{g}\right) z\left(t-\tau_{g}\right)-r_{2} x+c_{1} z\left(t-\tau_{g}\right), \\
& \frac{d y}{d t}=\frac{R_{3} N}{z}-R_{4} x\left(t-\tau_{i}\right)+C_{2}, \\
& \frac{d z}{d t}=R_{5}(y-\hat{y})(T-z)+R_{6} z(T-z)-R_{7} z,
\end{aligned}
$$

where $x(t)$ is the insulin concentration, $y(t)$ is the glucose concentration, $z(t)$ is the number of $\beta$-cells, and $\hat{y}$ is the difference between glucose fasting level and its basal level. $\tau_{g}$ is the delay in insulin secretion in response to blood glucose level increase based on clinical evidence reported by Palumbo et al. [33], and $\tau_{i}$ is the delay in glucose drop due to increased insulin level based on clinical evidence reported by Prager et al. [34]. $r_{1} y\left(t-\tau_{g}\right) z\left(t-\tau_{g}\right)$ shows the increase in insulin concentration in response to blood glucose increase with the time delay $\tau_{g} . r_{2} x$ is the rate of insulin decrease independent of glucose, and $c_{1} z\left(t-\tau_{g}\right)$ is the increase of insulin level secreted by $\beta$-cells and is independent from other components. System (3) considers two time lags in insulin-glucose regulatory system; therefore, it is more realistic and is capable of showing the behavior of insulin-glucose regulatory system in different time delays. Previous models cannot display the behavior of aforementioned biological system with respect to time delays.

According to the model presented by Molnar et al. [17], if insulin secretion decreases to $1 / N$ of the number of $\beta$-cells, designated by $N$, due to a reduction, then the blood glucose increases until insulin levels are restored to nearly normal standards. So the blood glucose level is a function of the $\beta$-cells' capacity $N / n$. $N$ is the normal number of $\beta$-cells. $R_{4} x\left(t-\tau_{i}\right)$ is the rate of glucose reduction in response to insulin secretion with the time delay $\tau_{i}$. $T$ is the total density of $\beta$-cells, and the term $R_{5}(y-\hat{y})(T-z)$ represents the increase in dividing $\beta$-cells caused by the interaction between blood glucose above the fasting level and the nondividing $\beta$-cells. The term $R_{6} z(T-z)$ represents the increase in $z$ due to interaction between dividing and nondividing $\beta$-cells, and the term $R_{7} z$ represents the reduction in $z$ due to its current level.

\section{Results and Discussion}

Based on the study by Chuedoung et al. [11], the mentioned model shows the different behaviors for different parameters. The proposed model comprises a number of parameters that their values are essential in changing the behavior of the system.

In current research, the new capability of the mentioned model is revealed. By increasing the insulin secretion delay by $\beta$-cells $\left(\tau_{g}\right)$, the system behaves in a chaotic way (Figure 2). Figure 2 is the bifurcation diagram of the system for the different values of $\tau_{g}$. Figure 2 shows that if there is more delay on insulin secretion, insulin cannot track glucose and the concentration of blood glucose rises which results in diabetes disorder. Technically speaking, the time lag of insulin response in glucose-insulin negative feedback controlling mechanism is shown to be the main reason for this disease. Computer simulation of Figure 2 is done by the following parameters $r_{1}=0.472, r_{2}=0.25, R_{3}=0.82, R_{4}=$ $0.6, R_{5}=0.3, R_{6}=0.3, R_{7}=0.2, c_{1}=0.1, C_{2}=0.8, \hat{y}=1.42$, 


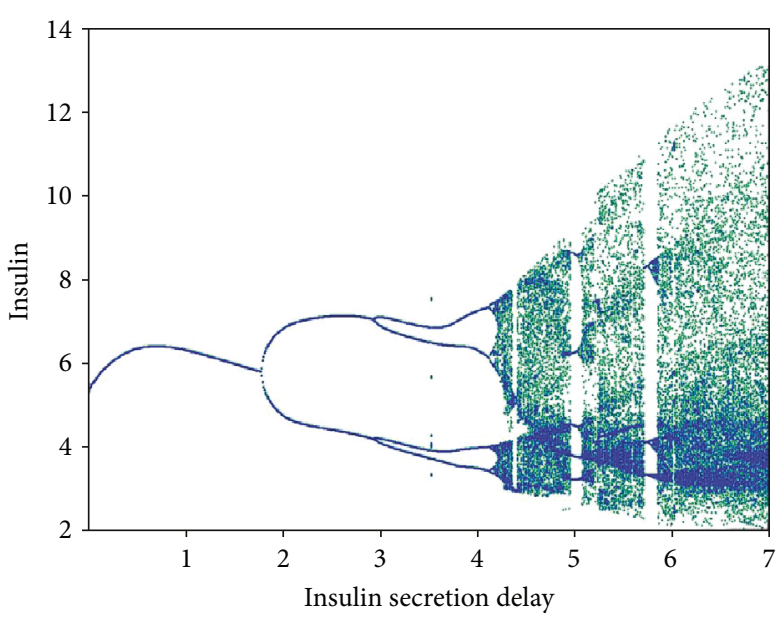

(a)

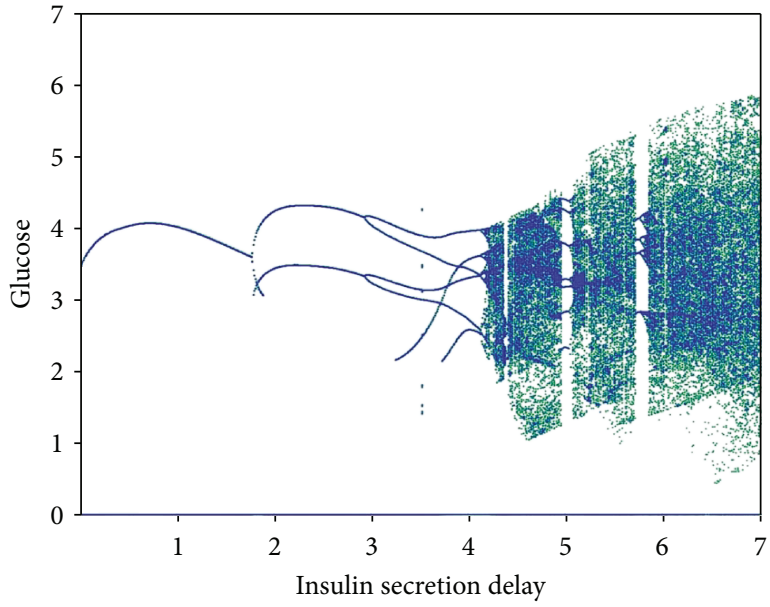

(b)

FIgURE 2: The model bifurcation diagrams based on different values of parameter $\tau_{g}$.

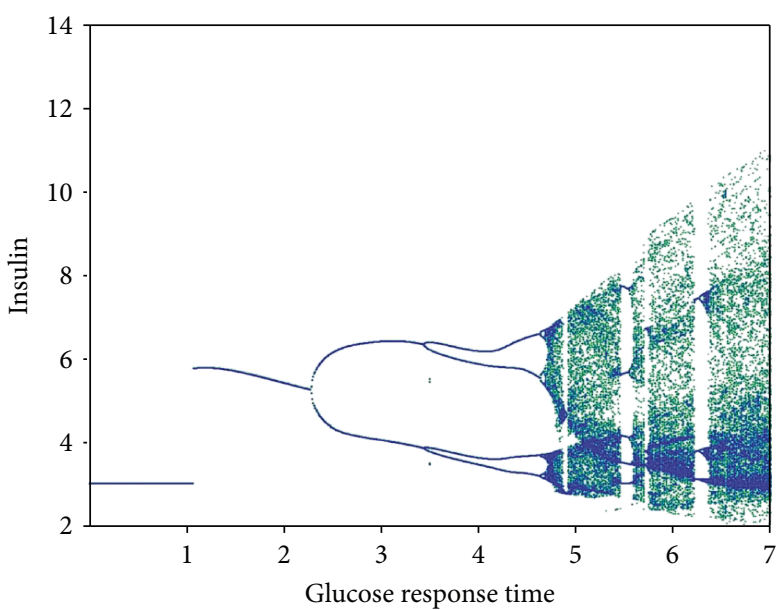

(a)

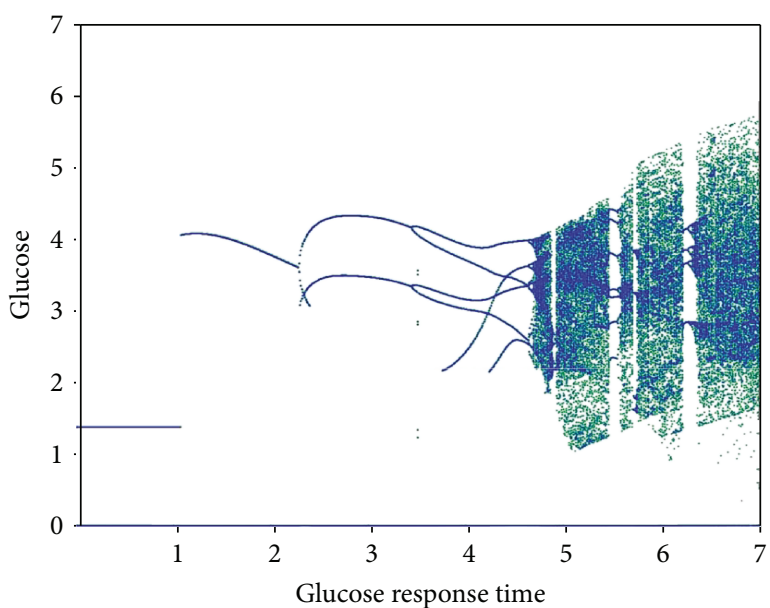

(b)

FIgURE 3: The model bifurcation diagrams based on different values of parameter $\tau_{i}$.

$T=1.5, N=1.27$, and $\tau_{i}=0.05$. The values of the parameters are the same as the values presented by Chuedoung et al. [11].

With the increase in glucose response time caused by insulin secretion $\left(\tau_{i}\right)$, the system behaves chaotically (Figure 3 ). Figure 3 is the bifurcation diagram of the system for different values of $\tau_{i}$. It shows that if there is more delay on response of glucose to insulin secretion, the system behaves in a chaotic manner. Note that the goal of this study is not to investigate the parameters quantitatively, but rather to show that a minute change in the quantities of parameters of the model can bring about changes in the behavior of the system. Computer simulation of Figure 3 is done by the following parameters $r_{1}$ $=0.472, r_{2}=0.25, R_{3}=0.82, R_{4}=0.6, R_{5}=0.3, R_{6}=0.3$, $R_{7}=0.2, \quad c_{1}=0.1, \quad C_{2}=0.8, \quad \hat{y}=1.42, \quad T=1.5, \quad N=1.27$, and $\tau_{g}=0.56$. The values of the parameters are the same as the values presented by Chuedoung et al. [11].
In the present study, we used the insulin-glucose model involving $\beta$-cells presented by Chuedoung et al. [11] and the effect of delays on insulin-glucose model have been investigated. The system is stable for small delays, and when the delays increase, the system exhibits chaotic behavior. According to the claim made by Bertram and Pernarowski [35], 1-2 min lag, representative of insulin secretion, is a common incident after bath application of glucose in islet electrical activity when investigating islet porosity and the permeability of a surrounding layer of acinar cells on the time required for glucose to diffuse through an isolated pancreatic islet of Langerhans and reach an equilibrium. And, based on a report by Forrest et al. [36], instantaneous insulin reflection was recorded in 14 out of the 20 monitored Jamaican children rehabilitated from malnutrition. The response time was about 1 minute for them; whereas, this delay ranged from 5 to 10 minutes for the other children. Hence, these observations support our claim about the range of $\tau_{g}$ and $\tau_{i}$. 


\section{Adaptive Sliding Mode Control}

A new sliding mode control scheme for a class of uncertain time-delay chaotic systems is proposed in [37]. It is shown that a linear time-invariant system with the desired system dynamics is used as a reference model for the output of a time-delay chaotic system to track. Chaos control for scalar-delayed chaotic systems using sliding mode control strategy is achieved in [38]. Sliding surface design is based on delayed feedback controller, and it is shown that the proposed controller can achieve stability for an arbitrary unstable fixed point (UPF) or unstable periodic orbit (UPO) with an arbitrary period.

In this section, we design the adaptive sliding mode controllers to suppress the chaotic oscillations in the model presented in (3). For the uncertainties, we assume that the parameters $r_{1}, r_{2}, c_{1}$, and $c_{2}$ are unknown. The entire control algorithm is designed with the delay elements as described in (3), and hence the sliding surface initialization is accounted with the respective time delays. Let us redefine the model in (3) with the controllers $u_{i}$, where $i=x, y, z$ as given in

$$
\begin{aligned}
& \dot{x}=r_{1} y\left(t-\tau_{g}\right) z\left(t-\tau_{g}\right)-r_{2} x+c_{1} z\left(t-\tau_{g}\right)+u_{x}, \\
& \dot{y}=\frac{R_{3} N}{z}-R_{4} x\left(t-\tau_{i}\right)+c_{2}+u_{y}, \\
& \dot{z}=R_{5}(y-\widehat{y})(T-z)+R_{6} z(T-z)-R_{7} z+u_{z} .
\end{aligned}
$$

We define the integral sliding mode surface as

$$
\begin{aligned}
& s_{x}=x+k_{x} \int_{0}^{t} x(\tau) d \tau, \\
& s_{y}=y+k_{y} \int_{0}^{t} y(\tau) d \tau, \\
& s_{z}=z+k_{z} \int_{0}^{t} z(\tau) d \tau .
\end{aligned}
$$

The sliding surface dynamics can be derived as

$$
\begin{aligned}
& \dot{s}_{x}=\dot{x}+k_{x} x, \\
& \dot{s}_{y}=\dot{y}+k_{y} y, \\
& \dot{s}_{z}=\dot{z}+k_{z} z .
\end{aligned}
$$

The parameter estimation errors are defined as

$$
\begin{aligned}
& e_{r_{1}}=\widehat{r}_{1}-r_{1}, \\
& e_{r_{2}}=\widehat{r}_{2}-r_{2}, \\
& e_{c_{1}}=\widehat{c}_{1}-c_{1}, \\
& e_{c_{2}}=\widehat{c}_{2}-c_{2} .
\end{aligned}
$$

The first derivatives of the estimation errors are

$$
\begin{aligned}
& \dot{e}_{r_{1}}=\dot{\hat{\vec{r}}}_{1}, \\
& \dot{e}_{r_{2}}=\dot{\hat{r}}_{2}, \\
& \dot{e}_{c_{1}}=\dot{\hat{c}}_{1}, \\
& \dot{e}_{c_{2}}=\dot{\hat{c}}_{2} .
\end{aligned}
$$

Consider the following Lyapunov function:

$$
V=\frac{1}{2}\left[s_{x}^{2}+s_{y}^{2}+s_{z}^{2}+e_{r_{1}}^{2}+e_{r_{2}}^{2}+e_{c_{1}}^{2}+e_{c_{2}}^{2}\right] .
$$

The first derivative of the Lyapunov candidate function is

$$
\dot{V}=s_{1} \dot{s}_{1}+s_{2} \dot{s}_{2}+s_{3} \dot{s}_{3}+e_{r_{1}} \dot{e}_{r_{1}}+e_{r_{2}} \dot{e}_{r_{2}}+e_{c_{1}} \dot{e}_{c_{1}}+e_{c_{2}} \dot{e}_{c_{2}}
$$

Applying (4), (6), and (8) in (10), we have

$$
\begin{aligned}
\dot{V}= & s_{x}\left[r_{1} y\left(t-\tau_{g}\right) z\left(t-\tau_{g}\right)-r_{2} x+c_{1} z\left(t-\tau_{g}\right)+u_{x}+k_{x} x\right] \\
& +s_{y}\left[\frac{R_{3} N}{z}-R_{4} x\left(t-\tau_{i}\right)+c_{2}+u_{y}+k_{y} y\right] \\
& +s_{z}\left[R_{5}(y-\widehat{y})(T-z)+R_{6} z(T-z)-R_{7} z+u_{z}+k_{z} z\right] \\
& +e_{r_{1}} \dot{\widehat{\vec{r}}}_{1}+e_{r_{2}} \dot{\hat{r}}_{2}+e_{c_{1}} \dot{\widehat{c}}_{1}+e_{c_{2}} \dot{\widehat{c}}_{2} .
\end{aligned}
$$

By introducing uncertainties without changing the definition in (11),

$$
\begin{aligned}
\dot{V}= & s_{x}\left[\begin{array}{c}
r_{1} y\left(t-\tau_{g}\right) z\left(t-\tau_{g}\right)+\widehat{r}_{1} y\left(t-\tau_{g}\right) z\left(t-\tau_{g}\right)-\widehat{r}_{1} y\left(t-\tau_{g}\right) z\left(t-\tau_{g}\right) \\
-r_{2} x+\widehat{r}_{2} x-\widehat{r}_{2} x+c_{1} z\left(t-\tau_{g}\right)+\widehat{c}_{1} z\left(t-\tau_{g}\right)-\widehat{c}_{1} z\left(t-\tau_{g}\right)+u_{x}+k_{x} x
\end{array}\right] \\
& +s_{y}\left[\frac{R_{3} N}{z}-R_{4} x\left(t-\tau_{i}\right)+c_{2}+\widehat{c}_{2}-\widehat{c}_{2}+u_{y}+k_{y} y\right] \\
& +s_{z}\left[R_{5}(y-\widehat{y})(T-z)+R_{6} z(T-z)-R_{7} z+u_{z}+k_{z} z\right]+e_{r_{1}} \dot{\widehat{r}}_{1}+e_{r_{2}} \dot{\hat{r}}_{2}+e_{c_{1}} \dot{\widehat{c}}_{1}+e_{c_{2}} \dot{\vec{c}}_{2} .
\end{aligned}
$$




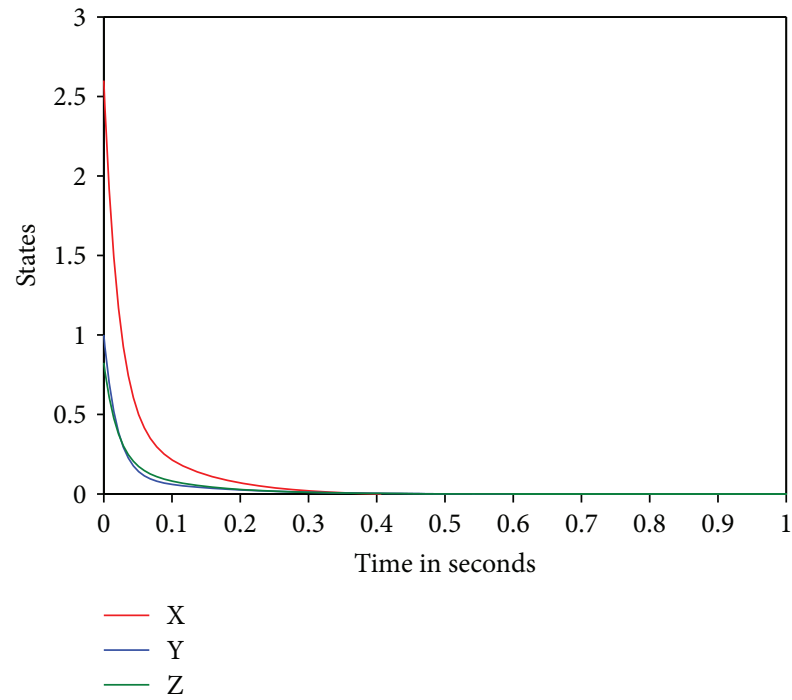

FIGURE 4: Time history of the states with control in action at $t=0 \mathrm{~s}$.

After some mathematical simplifications, let us define the adaptive sliding mode controllers as

$$
\begin{aligned}
u_{x}= & -\widehat{r}_{1} y\left(t-\tau_{g}\right) z\left(t-\tau_{g}\right)+\widehat{r}_{2} x-\widehat{c}_{1} z\left(t-\tau_{g}\right) \\
& -k_{x} x-\eta_{x} \operatorname{sgn}\left(s_{x}\right)-\rho_{x} s_{x}, \\
u_{y}= & -\frac{R_{3} N}{z}+R_{4} x\left(t-\tau_{i}\right)-\widehat{c}_{2}-k_{y} y-\eta_{y} \operatorname{sgn}\left(s_{y}\right)-\rho_{y} s_{y}, \\
u_{z}= & -R_{5}(y-\widehat{y})(T-z)-R_{6} z(T-z)+R_{7} z-k_{z} z \\
& -\eta_{z} \operatorname{sgn}\left(s_{z}\right)-\rho_{z} s_{z} .
\end{aligned}
$$

The parameter estimate laws can be defined as

$$
\begin{aligned}
& \dot{\widehat{r}}_{1}=s_{x} y\left(t-\tau_{g}\right) z\left(t-\tau_{g}\right), \\
& \dot{\vec{r}}_{2}=-s_{x} x, \\
& \dot{\widehat{c}}_{1}=s_{x} z\left(t-\tau_{g}\right), \\
& \dot{\vec{c}}_{2}=s_{y} .
\end{aligned}
$$

Using (13) and (14) in (12), we simplify the Lyapunov candidate function dynamics to

$$
\dot{V} \leq-\eta_{x}\left|s_{x}\right|-\eta_{y}\left|s_{y}\right|-\eta_{z}\left|s_{z}\right|-\rho_{x} s_{x}^{2}-\rho_{y} s_{y}^{2}-\rho_{z} s_{z}^{2}
$$

As $\rho_{i}$ and $\eta_{i}$ are positive for $i=x, y, z$, the Lyapunov first derivative (15) is a negative definite function which infers that the controller is stable as per the theorem discussed in $[39,40]$ and is valid for any bounded initial conditions. For numerical simulations, the initial conditions are taken as $2.6,1$, and 0.825 and the sliding surface initial conditions are defined as $-2.6,-1$, and -0.825 with the time delays

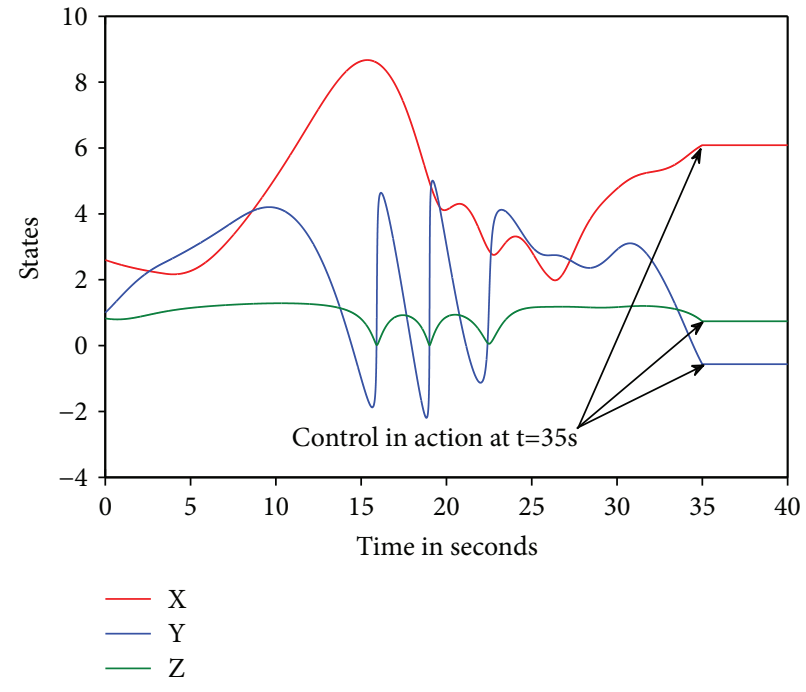

FIgURE 5: Time history of the states with control in action at $t=35 \mathrm{~s}$.

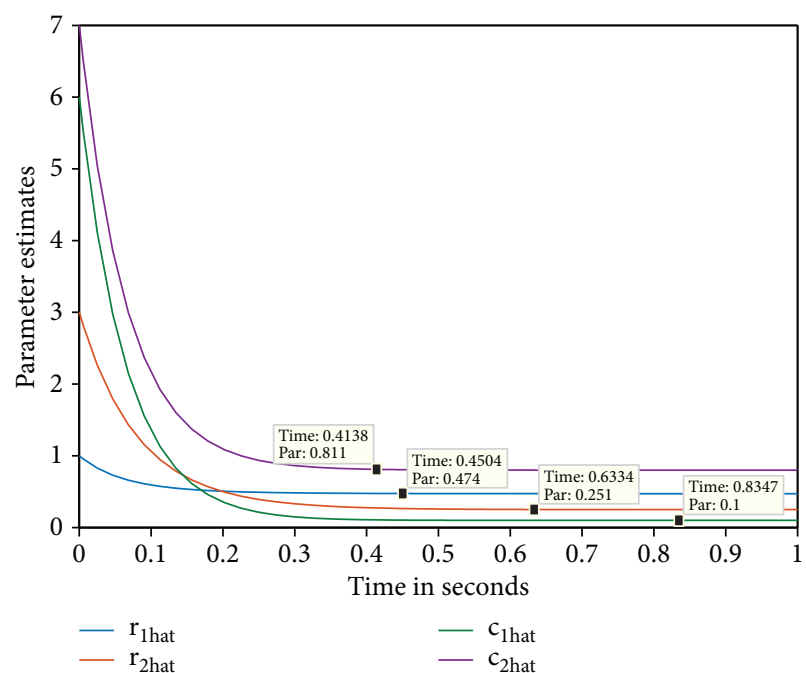

FIGURE 6: Time history of parameter estimates.

$\tau_{g}=3.56$ and $\tau_{i}=3.35$. The initial conditions of the parameter estimates are defined as $\widehat{r}_{1}=1, \widehat{r}_{2}=3, \widehat{c}_{1}=6$, and $\widehat{c}_{2}=7$. Figures 4 and 5 show the time history of states controlled with adaptive sliding mode controllers in action at $t=0 \mathrm{~s}$ and $t=35 \mathrm{~s}$, respectively. Figure 6 shows the estimated parameters with parameter update laws and controllers in action at $t=0 \mathrm{~s}$.

\section{FPGA Implementation}

Implementation of chaotic and hyperchaotic systems using Field Programmable Gate Arrays (FPGA) has been widely investigated [41-43]. Chaotic random number generators have been implemented in FPGA for applications in image cryptography [44]. FPGA-implemented Duffing oscillatorbased signal detectors have been proposed by Rashtchi et al. [45]. Digital implementations of chaotic multiscroll 


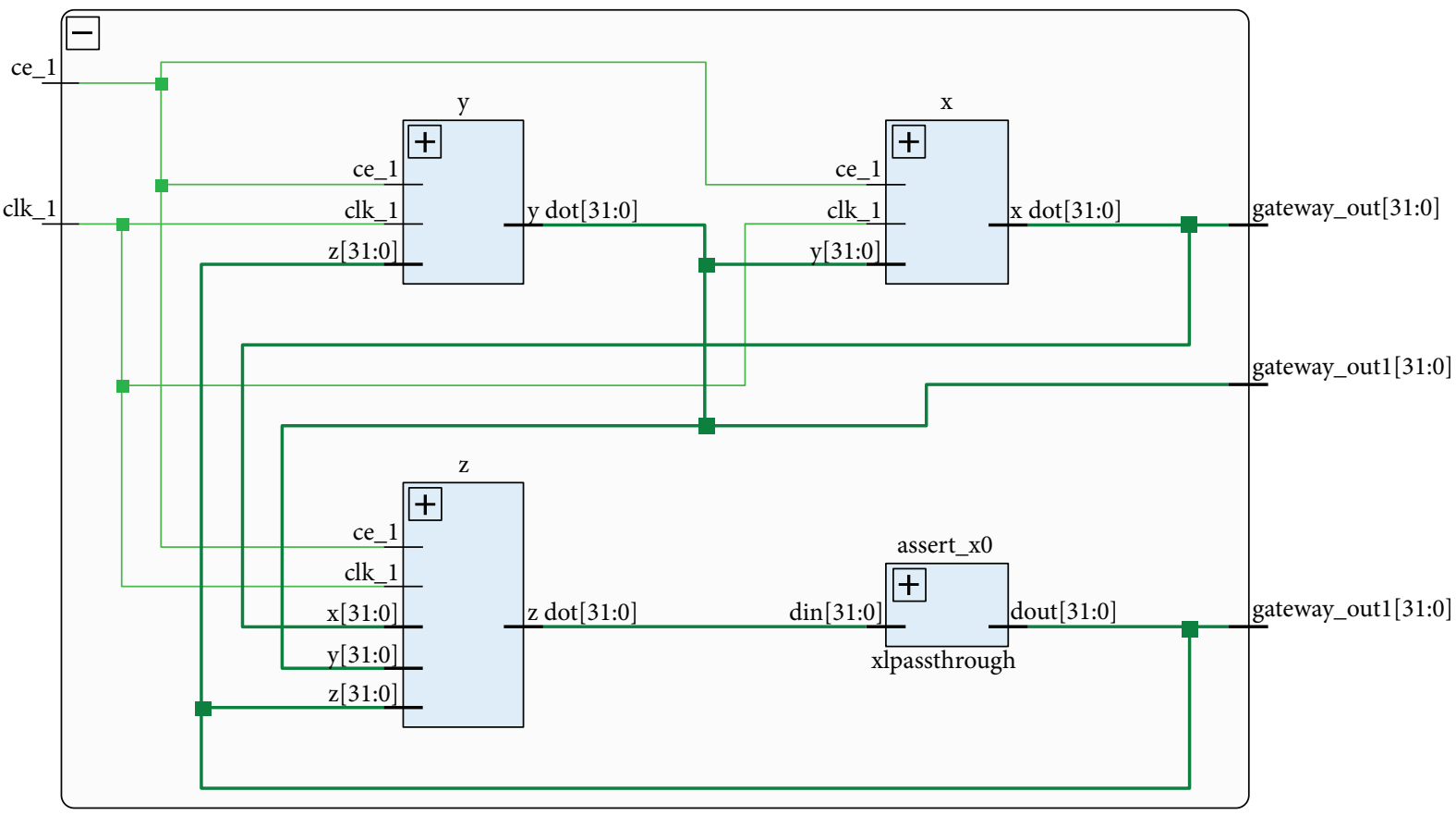

FIgURE 7: Overall RTL schematics of (3).

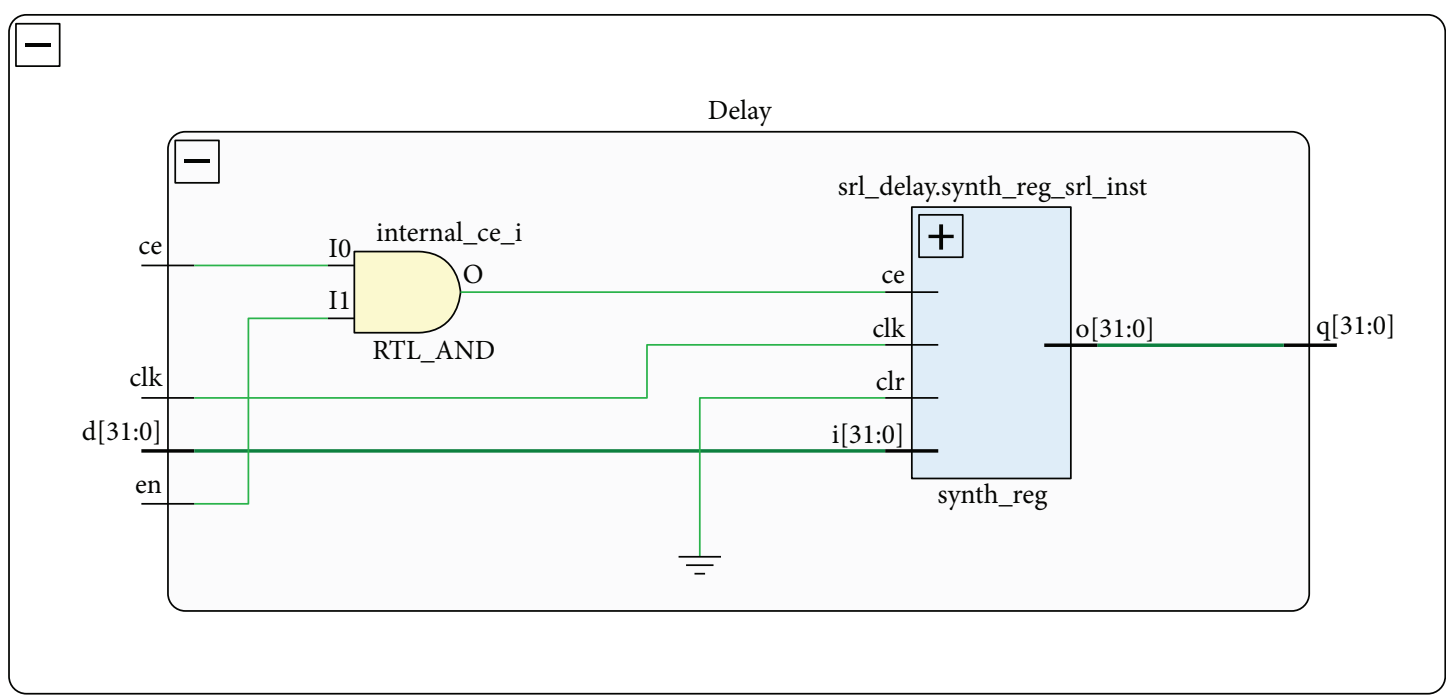

Figure 8: RTL schematics of the implemented delay (3).

attractors have been extensively investigated [41, 46]. Memristor-based chaotic system and its FPGA circuits have been proposed by Ya-Ming et al. [47]. A FPGA implementation of fractional order chaotic system using approximation method has been investigated by Rajagopal et al. [48-50].

In this section, we implement a circuit for the model (3) by FPGA. To the best of our knowledge, only a few literatures $[51,52]$ have implemented delay chaotic systems. However, those works discuss about indirect realizations which will increase the time slack factor as the programs run sequentially on the processor. But we use a direct realization, and hence the power utilization and the time slack delays are reduced. For the design of delay chaotic model (3), first, we configure the available built-in blocks of the System generator toolbox. The Add/Sub blocks are configured with zero latency and 32/16 bit fixed point settings. The delays are introduced by an additional delay block introduced with the defined time delays as in (3). The output of the block is configured to rounded quantization in order to reduce the bit latency. Then, we design the integer order integrator which is not a readily available block in the System Generator. Hence, we implement the integrators using the mathematical relation $\left(d x_{i} / d t\right)=\lim _{h \rightarrow 0}$ $\left(\left[x_{i}(n+1)-x_{i}(n)\right] / h\right)$ and the value of $h$ is taken as 0.001 . 


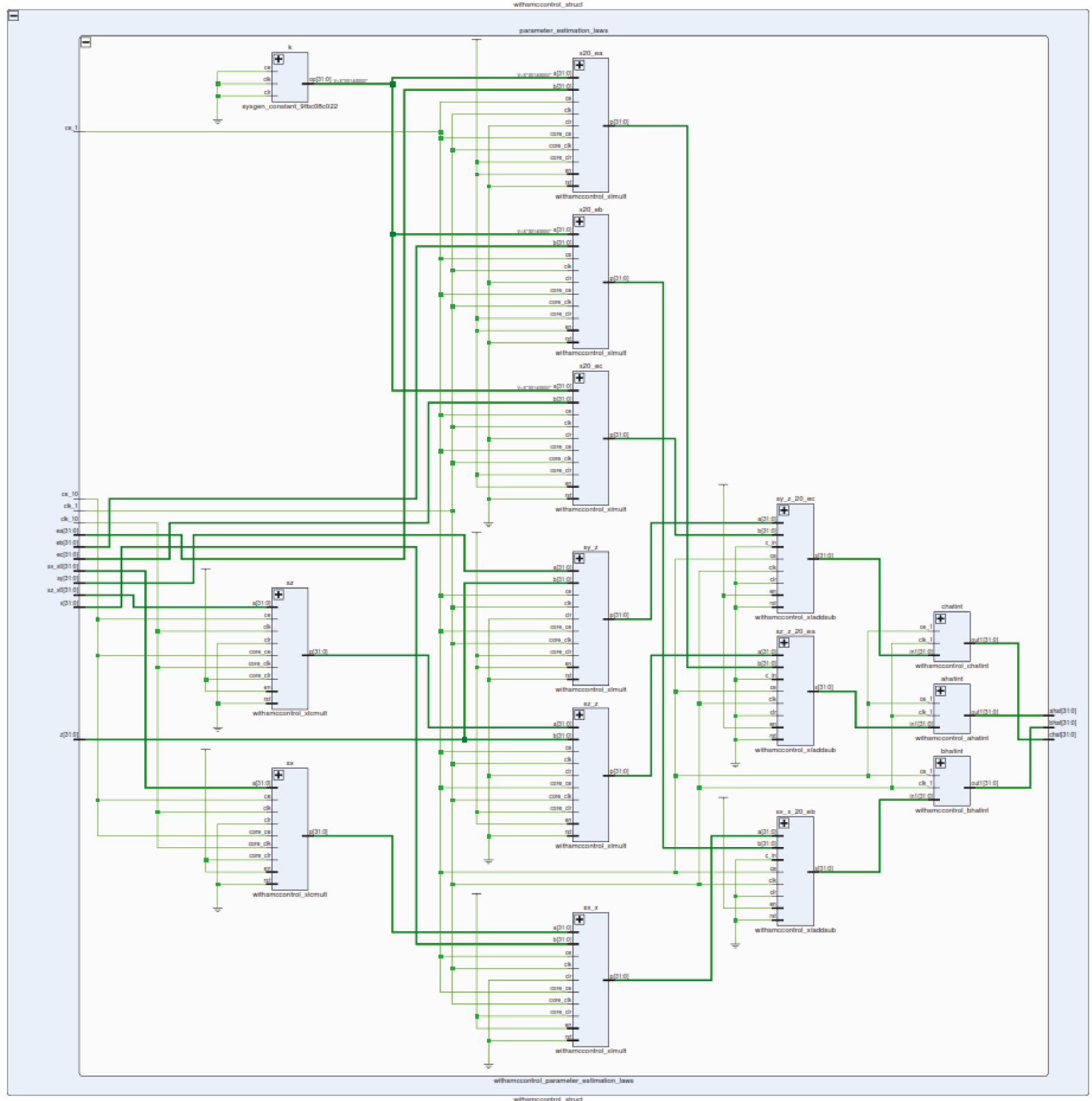

FIgURE 9: Xilinx RTL schematics of the controllers with sliding surfaces and parameter estimate laws.

The initial conditions are fed into the forward register. Figure 7 shows the overall RTL schematics of the system with time delays. Figure 8 shows the RTL schematics of the implemented delay (3). Figure 9 shows the Xilinx RTL schematics of the controllers with sliding surfaces and parameter estimate laws. Figures 10 and 11 show the controlled states of the delay systems and estimated parameters with the control in action at $t=0.5 \mathrm{~s}$, respectively.

\section{Discussion and Conclusion}

By studying presented mathematical models for glucoseinsulin interaction, according to the value of parameters, a chaotic model for describing the glucose-insulin regulatory system was found. In the present study, it is expected to observe periodic behavior in the proposed system under normal metabolic conditions and chaotic behavior under abnormal metabolic conditions. It is noteworthy to say that the chaotic behavior of a system is a sign of a faulty condition in the biological systems [18-23].

The effect of two time delays on glucose-insulin regulatory system was investigated. Two main results of this study are listed as below.

(i) If the time lag of insulin response to glucose increases, system exits from periodic region and enters to chaotic region, and if there is more delay on response of glucose to insulin secretion, the system displays chaotic manner, which was in line with previous studies $[35,36]$ 


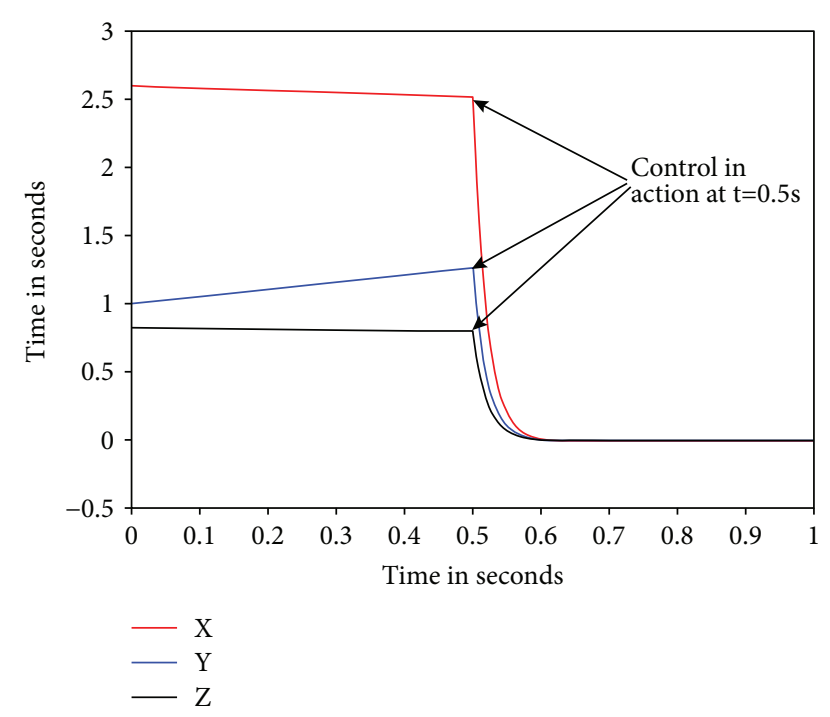

FIGURE 10: Time history of the delay (3) with controllers in action at $t=0.5 \mathrm{~s}$ using Xilinx system generator toolbox.

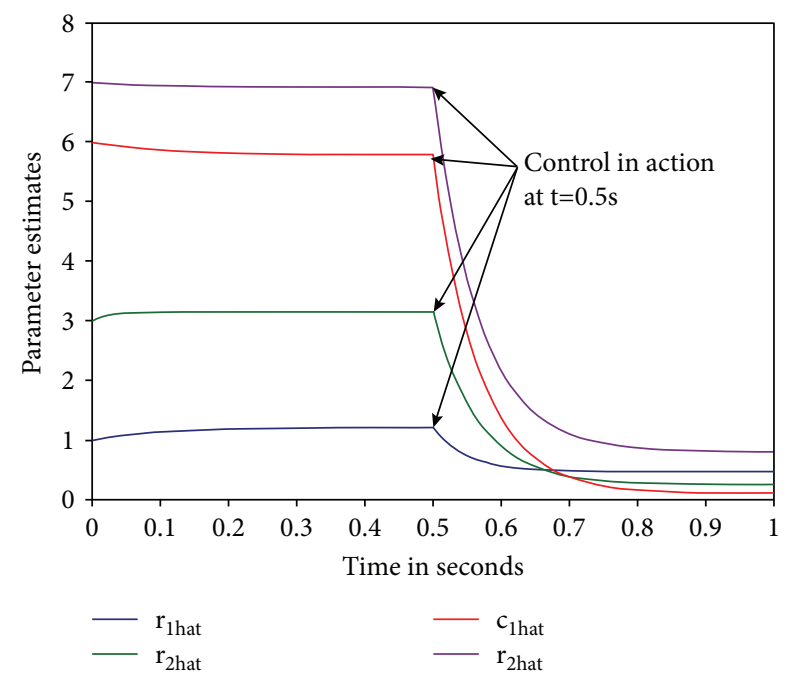

FIGURE 11: Time history of the parameter estimates with controllers in action at $t=0.5 \mathrm{~s}$ using Xilinx system generator toolbox.

(ii) If there is more delay on the response of glucose to insulin secretion, the behavior of system alters from periodic to chaotic

The proposed system can explain the interaction between glucose and insulin concentration in both normal and abnormal (diabetes disease) situations. Also, a control method was investigated with the hope of possible clinical applications.

\section{Conflicts of Interest}

The authors declare that they have no conflicts of interest.

\section{References}

[1] Wikipedia, "Diabetes mellitus," 2017, January 2017, https://en. wikipedia.org/wiki/Diabetes_mellitus.
[2] National Institute of Diabetes and Digestive and Kidney Diseases, "Diabetes," 2017, January 2017, https://www.niddk. nih.gov/health-information/diabetes.

[3] Canadian Diabetes Association, "Types of diabetes," 2017, January 2017, http://www.diabetes.ca/about-diabetes/typesof-diabetes.

[4] A. Hess-Fischl and L. M. Leontis, "Type 2 diabetes: key facts," January 2017, http://www.endocrineweb.com/conditions/type2-diabetes/type-2-diabetes-overview.

[5] D. E. Smith-Marsh, “Type 1 diabetes overview," 2017, January 2017, http://www.endocrineweb.com/conditions/type-1-diabe tes/type-1-diabetes-overview.

[6] T. A. Holt, "Nonlinear dynamics and diabetes control," The Endocrinologist, vol. 13, no. 6, pp. 452-456, 2003.

[7] L. Heinemann, K. Sinha, C. Weyer, M. Loftager, S. Hirschberger, and T. Heise, "Time-action profile of the soluble, fatty acid acylated, long-acting insulin analogue NN304," Diabetic Medicine, vol. 16, no. 4, pp. 332-338, 1999.

[8] I. F. GODSLAND and C. WALTON, "Maximizing the success rate of minimal model insulin sensitivity measurement in humans: the importance of basal glucose levels," Clinical Science, vol. 101, no. 1, pp. 1-9, 2001.

[9] T. Deutsch, E. D. Lehmann, E. R. Carson, A. V. Roudsari, K. D. Hopkins, and P. H. Sönksen, "Time series analysis and control of blood glucose levels in diabetic patients," Computer Methods and Programs in Biomedicine, vol. 41, no. 3-4, pp. 167-182, 1994.

[10] J. J. Liszka-Hackzell, "Prediction of blood glucose levels in diabetic patients using a hybrid AI technique," Computers and Biomedical Research, vol. 32, no. 2, pp. 132-144, 1999.

[11] M. Chuedoung, W. Sarika, and Y. Lenbury, "Dynamical analysis of a nonlinear model for glucose-insulin system incorporating delays and $\beta$-cells compartment," Nonlinear Analysis: Theory, Methods \& Applications, vol. 71, no. 12, pp. e1048-e1058, 2009.

[12] L. Sherwood, "Human Physiology: from Cell to systems," Cengage Learning, Boston, MA, USA, 2015.

[13] Y. Lenbury, S. Ruktamatakul, and S. Amornsamarnkul, "Modeling insulin kinetics: responses to a single oral glucose administration or ambulatory-fed conditions," Biosystems, vol. 59, no. 1, pp. 15-25, 2001.

[14] C. Geevan, J. Subba Rao, G. S. Rao, and J. S. Bajaj, “A mathematical model for insulin kinetics III. Sensitivity analysis of the model," Journal of Theoretical Biology, vol. 147, no. 2, pp. 255-263, 1990.

[15] J. Bajaj, G. S. Rao, J. Subba Rao, and R. Khardori, "A mathematical model for insulin kinetics and its application to protein-deficient (malnutrition-related) diabetes mellitus (PDDM)," Journal of Theoretical Biology, vol. 126, no. 4, pp. 491-503, 1987.

[16] E. Ackerman, J. W. Rosevear, and W. F. McGuckin, "A mathematical model of the glucose-tolerance test," Physics in Medicine and Biology, vol. 9, no. 2, pp. 203-213, 1964.

[17] G. Molnar, W. Taylor, and A. Langworthy, "Plasma immunoreactive insulin patterns in insulin-treated diabetics. Studies during continuous blood glucose monitoring," Mayo Clinic proceedings, vol. 47, no. 10, pp. 709-719, 1972.

[18] W. J. Freeman, "The physiology of perception," Scientific American, vol. 264, no. 2, pp. 78-85, 1991. 
[19] J. Ulbikas, A. Čenys, and O. Sulimova, "Chaos parameters for EEG analysis," Nonlinear Analysis: Modelling and Control, no. 2, pp. 141-148, 1998.

[20] W. J. Freeman, "Strange attractors that govern mammalian brain dynamics shown by trajectories of electroencephalographic (EEG) potential," IEEE Transactions on Circuits and Systems, vol. 35, no. 7, pp. 781-783, 1988.

[21] P. Faure and H. Korn, "Is there chaos in the brain? I. Concepts of nonlinear dynamics and methods of investigation," Comptes Rendus de l'Académie des Sciences-Series III-Sciences de la Vie, vol. 324, no. 9, pp. 773-793, 2001.

[22] H. Korn and P. Faure, "Is there chaos in the brain? II. Experimental evidence and related models," Comptes Rendus Biologies, vol. 326, no. 9, pp. 787-840, 2003.

[23] G. Baghdadi, S. Jafari, J. C. Sprott, F. Towhidkhah, and M. R. Hashemi Golpayegani, "A chaotic model of sustaining attention problem in attention deficit disorder," Communications in Nonlinear Science and Numerical Simulation, vol. 20, no. 1, pp. 174-185, 2015.

[24] C. Grebogi and J. A. Yorke, Impact of Chaos on Science and Society, United Nations Publications, 1997.

[25] L. Glass and W. Z. Zeng, "Complex bifurcations and chaos in simple theoretical models of cardiac oscillations," Annals of the New York Academy of Sciences, vol. 591, pp. 316-327, 1990.

[26] T. R. Chay and J. Rinzel, "Bursting, beating, and chaos in an excitable membrane model," Biophysical Journal, vol. 47, no. 3, pp. 357-366, 1985.

[27] J. E. Skinner, S. G. Wolf, J. Y. Kresh, I. Izrailtyan, J. A. Armour, and M. H. Huang, "Application of chaos theory to a model biological system: evidence of self-organization in the intrinsic cardiac nervous system," Integrative Physiological and Behavioral Science, vol. 31, no. 2, pp. 122-146, 1996.

[28] W. Sarikaa, Y. Lenbury, K. Kumnungkit, and W. Kunphasuruang, "Modelling glucose-insulin feedback signal interchanges involving $\beta$-cells with delays," vol. 34, pp. 77-86, 2008.

[29] J. Li, Y. Kuang, and C. C. Mason, "Modeling the glucoseinsulin regulatory system and ultradian insulin secretory oscillations with two explicit time delays," Journal of Theoretical Biology, vol. 242, no. 3, pp. 722-735, 2006.

[30] A. Mukhopadhyay, A. De Gaetano, and O. Arino, "Modeling the intra-venous glucose tolerance test: a global study for a single-distributed-delay model," Discrete \& Continuous Dynamical Systems Series B, vol. 4, no. 2, pp. 407-417, 2004.

[31] D. Bennett and S. Gourley, "Asymptotic properties of a delay differential equation model for the interaction of glucose with plasma and interstitial insulin," Applied Mathematics and Computation, vol. 151, no. 1, pp. 189-207, 2004.

[32] K. Engelborghs, V. Lemaire, J. Bélair, and D. Roose, "Numerical bifurcation analysis of delay differential equations arising from physiological modeling," Journal of Mathematical Biology, vol. 42, no. 4, pp. 361-385, 2001.

[33] P. Palumbo, S. Panunzi, and A. De Gaetano, "Qualitative behavior of a family of delay-differential models of the glucose-insulin system," Discrete and Continuous Dynamical Systems Series B, vol. 7, no. 2, pp. 399-424, 2007.

[34] R. Prager, P. Wallace, and J. M. Olefsky, "In vivo kinetics of insulin action on peripheral glucose disposal and hepatic glucose output in normal and obese subjects," Journal of Clinical Investigation, vol. 78, no. 2, pp. 472-481, 1986.
[35] R. Bertram and M. Pernarowski, "Glucose diffusion in pancreatic islets of Langerhans," Biophysical Journal, vol. 74, no. 4, pp. 1722-1731, 1998.

[36] E. Forrest, P. Robinson, and M. Hazel, Insulin, Growth Hormone and Carbohydrate Tolerance in Jamaican Children Rehabilitated from Severe Malnutrition, MedCarib.

[37] L. Li-xiang, P. Hai-peng, G. Bao-zhu, and X. Jin-ming, “A new sliding mode control for a class of uncertain time-delay chaotic systems," Chinese Physics, vol. 10, no. 8, pp. 708-710, 2001.

[38] N. Vasegh and A. K. Sedigh, "Chaos control in delayed chaotic systems via sliding mode based delayed feedback," Chaos, Solitons \& Fractals, vol. 40, no. 1, pp. 159-165, 2009.

[39] M. Prakash and P. Balasubramaniam, "Stability and Hopf bifurcation analysis of novel hyperchaotic system with delayed feedback control," Complexity, vol. 21, no. 6, 193 pages, 2015.

[40] M. C. Pai, "Chaos control of uncertain time-delay chaotic systems with input dead-zone nonlinearity," Complexity, vol. 21, no. 3, 20 pages, 2014.

[41] E. Tlelo-Cuautle, A. D. Pano-Azucena, and J. J. RangelMagdaleno, "Generating a 50-scroll chaotic attractor at $66 \mathrm{MHz}$ by using FPGAs," Nonlinear Dynamics, vol. 85, no. 4, pp. 2143-2157, 2016.

[42] Q. Wang, S. Yu, and C. Li, "Theoretical design and FPGAbased implementation of higher-dimensional digital chaotic systems," IEEE Transactions on Circuits and Systems I: Regular Papers, vol. 63, no. 3, pp. 401-412, 2016.

[43] E. Dong, Z. Liang, S. Du, and Z. Chen, "Topological horseshoe analysis on a four-wing chaotic attractor and its FPGA implement," Nonlinear Dynamics, vol. 83, no. 1-2, pp. 623-630, 2016.

[44] E. Tlelo-Cuautle, V. H. Carbajal-Gomez, and P. J. ObesoRodelo, "FPGA realization of a chaotic communication system applied to image processing," Nonlinear Dynamics, vol. 82, no. 4, pp. 1879-1892, 2015.

[45] V. Rashtchi and M. Nourazar, "FPGA implementation of a real-time weak signal detector using a duffing oscillator," Circuits Systems and Signal Processing, vol. 34, no. 10, pp. 3101-3119, 2015.

[46] E. Tlelo-Cuautle, J. J. Rangel-Magdaleno, A. D. Pano-Azucena, P. J. Obeso-Rodelo, and J. C. Nunez-Perez, "FPGA realization of multi-scroll chaotic oscillators," Communications in Nonlinear Science and Numerical Simulation, vol. 27, no. 1-3, pp. 66-80, 2015.

[47] X. Ya-Ming, W. Li-Dan, and D. Shu-Kai, "A memristor-based chaotic system and its field programmable gate array implementation," Acta Physica Sinica, vol. 65, p. 12, 2016.

[48] R. Karthikeyan, A. Prasina, R. Babu, and S. Raghavendran, "FPGA implementation of novel synchronization methodology for a new chaotic system," Indian Journal of Science and Technology, vol. 8, no. 11, 2015.

[49] K. Rajagopal, A. Karthikeyan, and A. Srinivasan, "FPGA implementation of novel fractional-order chaotic systems with two equilibriums and no equilibrium and its adaptive sliding mode synchronization," Nonlinear Dynamics, vol. 87 , no. 4 , pp. 2281-2304, 2017.

[50] K. Rajagopal, A. Karthikeyan, L. Guessas, S. Vaidyanathan, and A. Srinivasan, "Dynamical analysis and FPGA implementation of a novel hyperchaotic system and its synchronization 
using adaptive sliding mode control and genetically optimized PID control," Mathematical Problems in Engineering, vol. 2017, Article ID 7307452, 14 pages, 2017.

[51] D. Valli, S. Banerjee, K. Ganesan, B. Muthuswamy, and C. K. Subramaniam, "Chaotic time delay systems and field programmable gate array realization," in Chaos, Complexity and Leadership 2012, Springer Proceedings in Complexity, S. Banerjee and Ş. Erçetin, Eds., Springer, Dordrecht, 2014.

[52] V. T. Pham, M. Frasca, L. Fortuna, T. T. Anh, and T. M. Hoang, "Realization of synchronization of coupled multiple delay systems on FPGA platform," in Proceedings of the Joint INDS'11 \& ISTET'11, pp. 1-5, Klagenfurt, Austria, July 2011. 


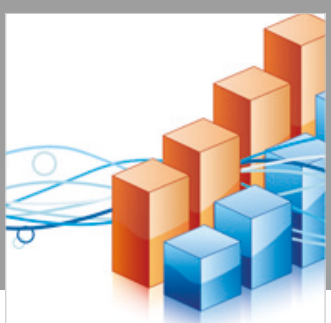

Advances in

Operations Research

\section{-n-m}
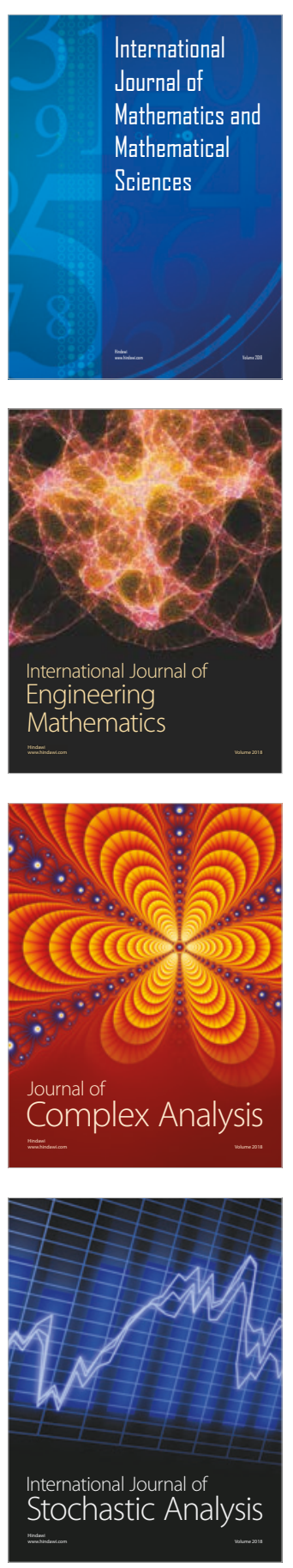
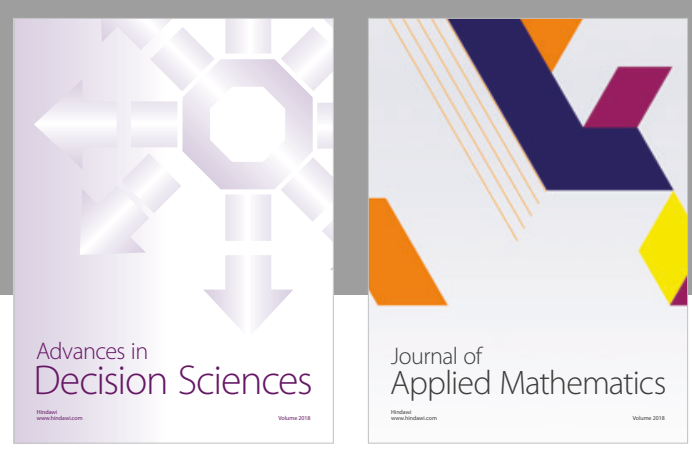

Journal of

Applied Mathematics
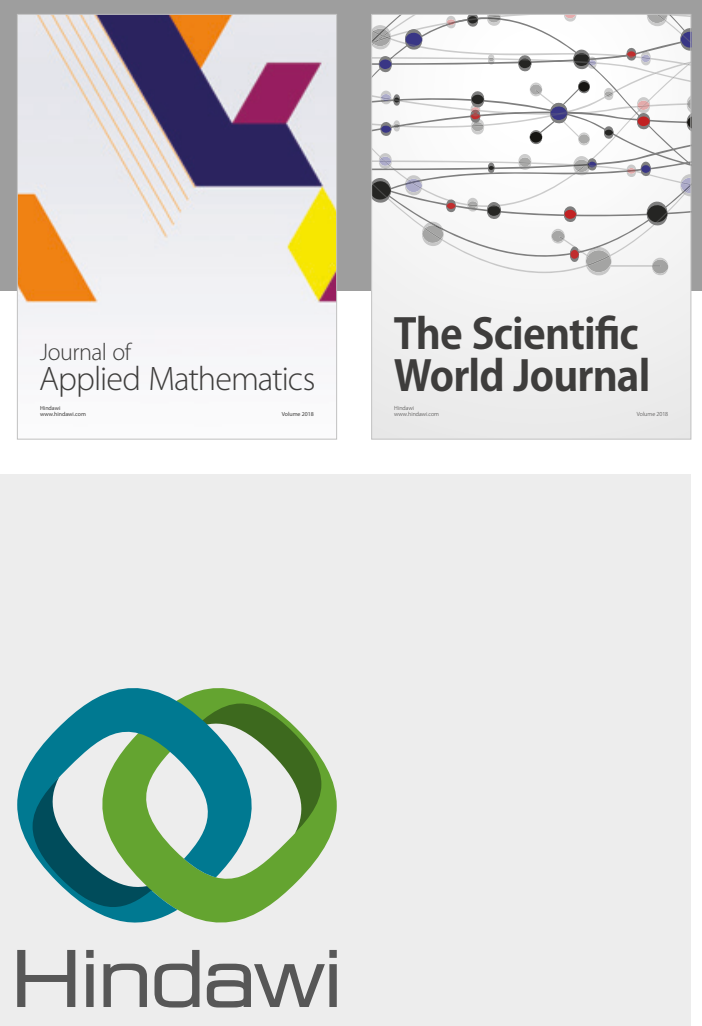

Submit your manuscripts at

www.hindawi.com

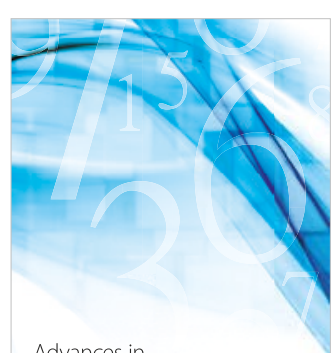

Advances in
Numerical Analysis
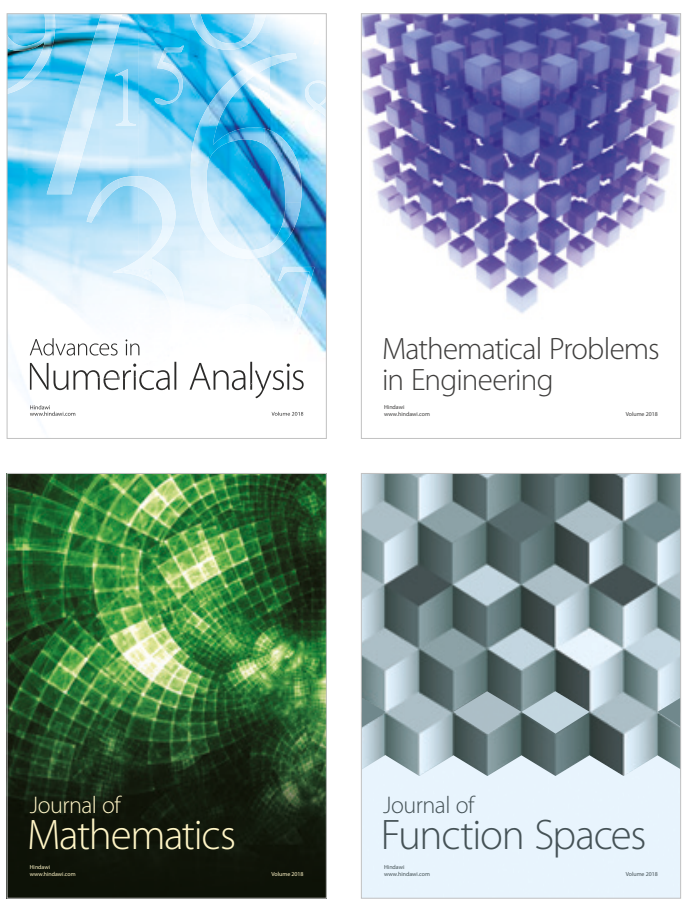

Mathematical Problems in Engineering

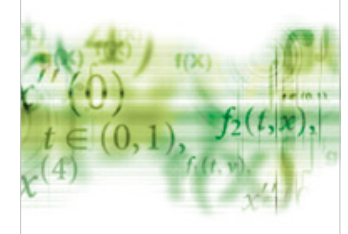

International Journal of

Differential Equations

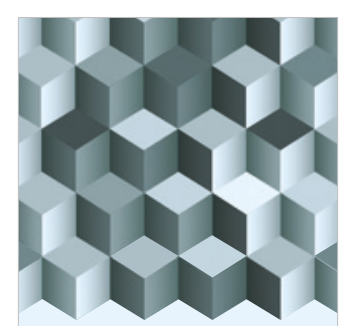

Journal of

Function Spaces
The Scientific

World Journal

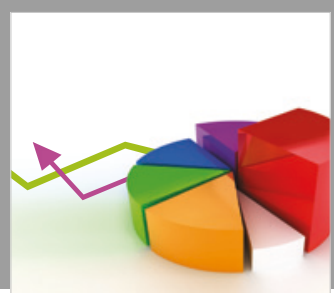

Journal of

Probability and Statistics
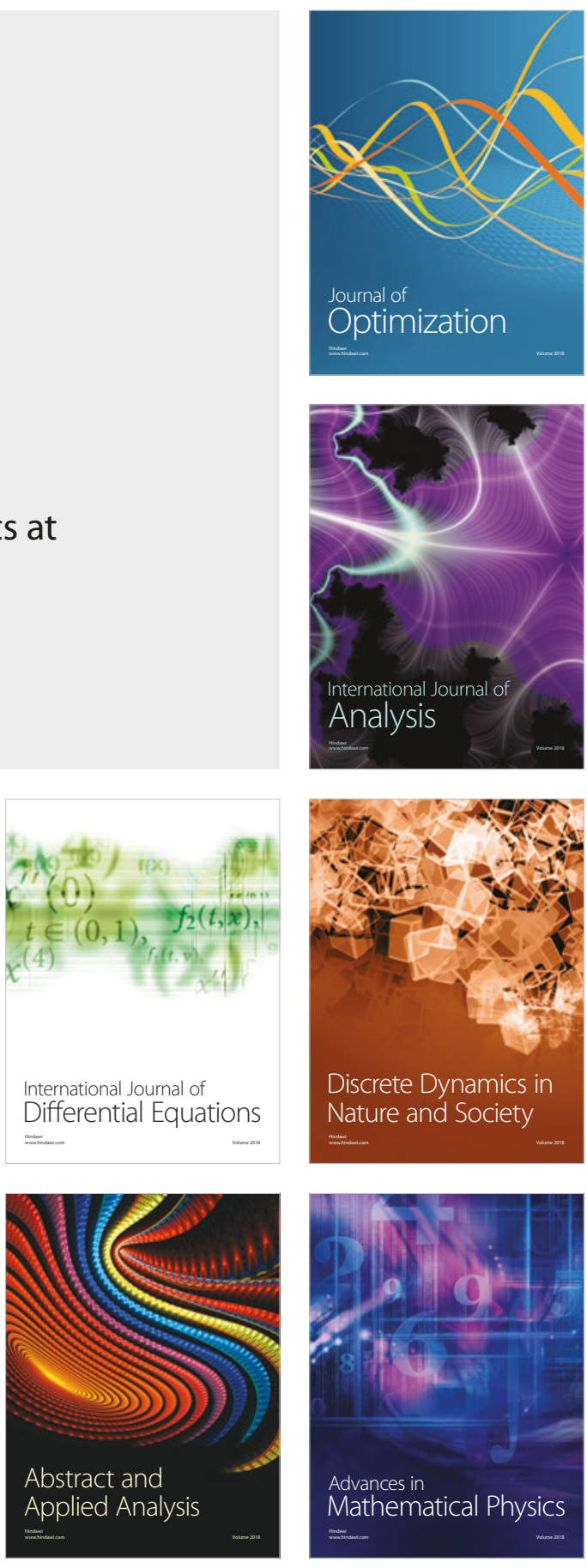